\title{
PVT properties variation with depth in carbonate reservoirs: a case study
}

\author{
Mohammad Ali Kargarpour ${ }^{1}$ (1)
}

Received: 14 January 2020 / Accepted: 27 May 2020 / Published online: 15 June 2020

(c) The Author(s) 2020

\begin{abstract}
PVT properties of a hydrocarbon reservoir, in addition to estimate oil and gas in place, are required for optimum dynamic reservoir management. In carbonate reservoirs, it is more important as reservoir's fluid properties usually vary laterally or/ and vertically. In this paper, summary results of a study which carried out on the reported PVT properties of reservoir 'A' are presented. Reservoir 'A' is a real oil carbonate reservoir which suffers from variation of PVT properties. The oil gravity and GOR (gas-oil ratio) in this reservoir are reported to be in the range of $23^{\circ}-36^{\circ}$ API and 300-1400 SCF/STB (Standard Cubic Feet/Stock Tank Barrel), respectively. These wide ranges of PVT properties raised questions about the accuracy and consistency of PVT laboratory test results, FBDST (Full Bore Drill Stem Test) measured data and reservoir characterization, such as effect of seismic recognized faults and the validity of laboratory PVT measurements which conducted on the reservoir fluid samples gathered from adjacent wells in one zone. So, an extensive, systematic study has been conducted on the available fluid data to check the validity of data and find out an acceptable, logical hypothesis about PVT variation across the reservoir, vertically and/or laterally. This study reveals that the reported laboratory measured PVT analysis, oil API gravity and GOR (gas oil ratio) measured in well tests campaign are valid. The PVT variation is dominantly vertical

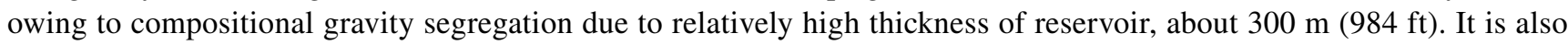
distinguished that seismic detected faults (if exist) do not act as barriers at least at geological time.
\end{abstract}

Keywords PVT variation $\cdot$ PVT validity $\cdot$ PVT properties $\cdot$ Faults $\cdot$ Carbonate reservoir

\section{Introduction}

Having a clear view and recognition of fluid properties is essential for an optimized and dynamic management of a hydrocarbon reservoir. During last decades, availability of new and robust reservoir simulation models adds to the value of having good information of reservoir fluid across the field. So, tens of million dollars are spent for gathering down-hole or surface fluid samples and laboratory tests. In addition, during production flow tests and/or Full Bore Drill Stem Tests (FBDST), a lot of on-site tests are conducted to measure a few properties of produced reservoir's fluid such as API gravity, $\mathrm{H}_{2} \mathrm{~S}$ and $\mathrm{CO}_{2}$ contents. In this expensive campaign of reservoir's fluid characterization, in addition to determine the details of fluid properties, it is expected to

Mohammad Ali Kargarpour

kargarpour2000@yahoo.com

1 Department of Petroleum Engineering, Petroleum Engineering and Development Company, Tehran, Iran answer questions such as: 'is reservoir fluid homogeneous throughout the reservoir?'; 'Is there any significant property variation with depth in the reservoir?' By increasing thickness and/or extend of reservoir, recognizing the variation of fluid properties, vertically or laterally, becomes more important. The author has encountered giant reservoirs where just because of difference in reservoir's fluid properties in lateral extent of reservoir, they are considered compartmentalized reservoirs for managing them from first years of production. So, great efforts are made to understand variation of reservoir's fluid properties. The fluid properties can basically change in vertical or lateral extent of a reservoir, among other factors, due to gravity, thermal diffusion and convection. Of course, barrier fault can affect the reservoir fluid properties. Whitson and Belery (1994), in addition to reviewing the works relevant to effect of gravity on the fluid segregation in a reservoir, by some examples showed that thermal diffusion can have a marked effect on compositional grading, with the possibility of enhancing, reducing, or completely eliminating gradients caused by gravity alone. Saidi 
(1987) believed that in well-to-moderately fractured reservoirs, where the oil in the vertical fractures convects due to the temperature gradient, we encounter with the bubble point pressure depression or elevation. He (Saidi 1987) also added that the main convective force circulating the oil in the fissures is the temperature gradient prevailing in the reservoir.

The author had a chance to come across a discussion about fluid properties of a reservoir. It was a dispute over the validity of laboratory results obtained from different sets of PVT samples gathered from down-hole and/or surface separator of different wells. It was wondered how to explain the differences in fluid properties reported by laboratories. It was supposed that the results may have some errors. To find out reasons for these discrepancies or source of errors, a methodological study is carried out. It is supposed other petroleum/reservoir engineers may encounter the same issue; thus, it is decided to share this experience with others. In the following sections, the author presents the data, general information and inquiries of this real case, followed by the methodology employed to answer raised questions. For sake of confidentiality, all names including reservoir, field, formations, layers and other relevant information are presented in alphabetically way.

\section{Field data}

Reservoir ' $A$ ' of the field is a carbonate reservoir with an average thickness of about $600 \mathrm{~m}$ (from 3950 to 4550 mss, meter subsea) and dimension of about $20 \mathrm{~km}$ times $10 \mathrm{~km}$ (see Fig. 1). This reservoir belongs to the Cenomanian-Turonian-aged formation group. There is an argillaceous limestone layer with thickness about $7 \mathrm{~m}$ which divides the reservoir to two parts (upper and lower), with approximately equal thickness (each part thickness is about $300 \mathrm{~m}$, in average). This argillaceous layer in other similar adjacent reservoirs behaves as a barrier in some instances; however, in a few other reservoirs, it is a conductive layer. By drilling and testing the first exploration well ('A-1' well), two different phenomena, non-supporting each other, have been observed. Measured reservoir fluid properties (gas-oil ratio, GOR, and API gravity) in upper and lower parts of the reservoir were significantly different; however, pressure of two tested intervals was the same at one datum depth; it means one pressure system governs upper and lower sections of the reservoir. Based on the geological understanding of the reservoir and existence of the above-mentioned argillaceous limestone layer, it was not surprising to suppose that the argillaceous limestone layer is a barrier one but two parts have same aquifer. However, as the fluid samples were gathered from outlet of surface separator during well tests, a few experts had serious doubts as to whether this is the case. During development period, several other wells have been drilled and tested. PVT laboratory tests of down-hole fluid samples and well site measured API gravities during conducting FBDSTs worsened the case as a diversity of fluid properties have been reported across the reservoir, vertically and laterally. Seismic data interpretation reveals two major thrust faults with North-West to South-East trends penetrating through the reservoir (refer to Fig. 1); however, their effects have not been detected in transient well test results. On the other hand, as faults are interpreted from 2D seismic, there are some degrees of uncertainties about their properties. A summary of measured fluid properties of the reservoir are shown in Tables 1 and 2. In Table 1, a results' summary of laboratory PVT tests which have been conducted on the two phase samples gathered from outlet of portable well head separator or single phase samples gathered from
Fig. 1 Schematic well locations of reservoir 'A' (not in scale)

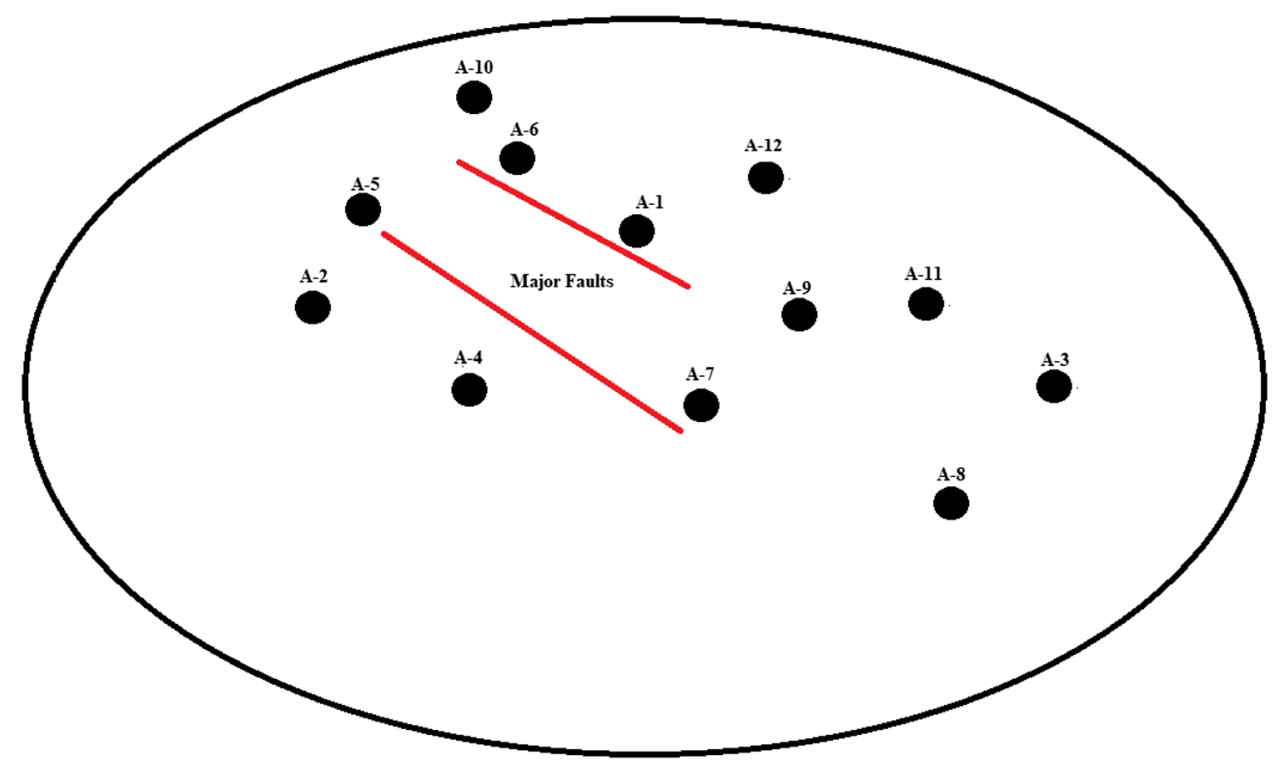




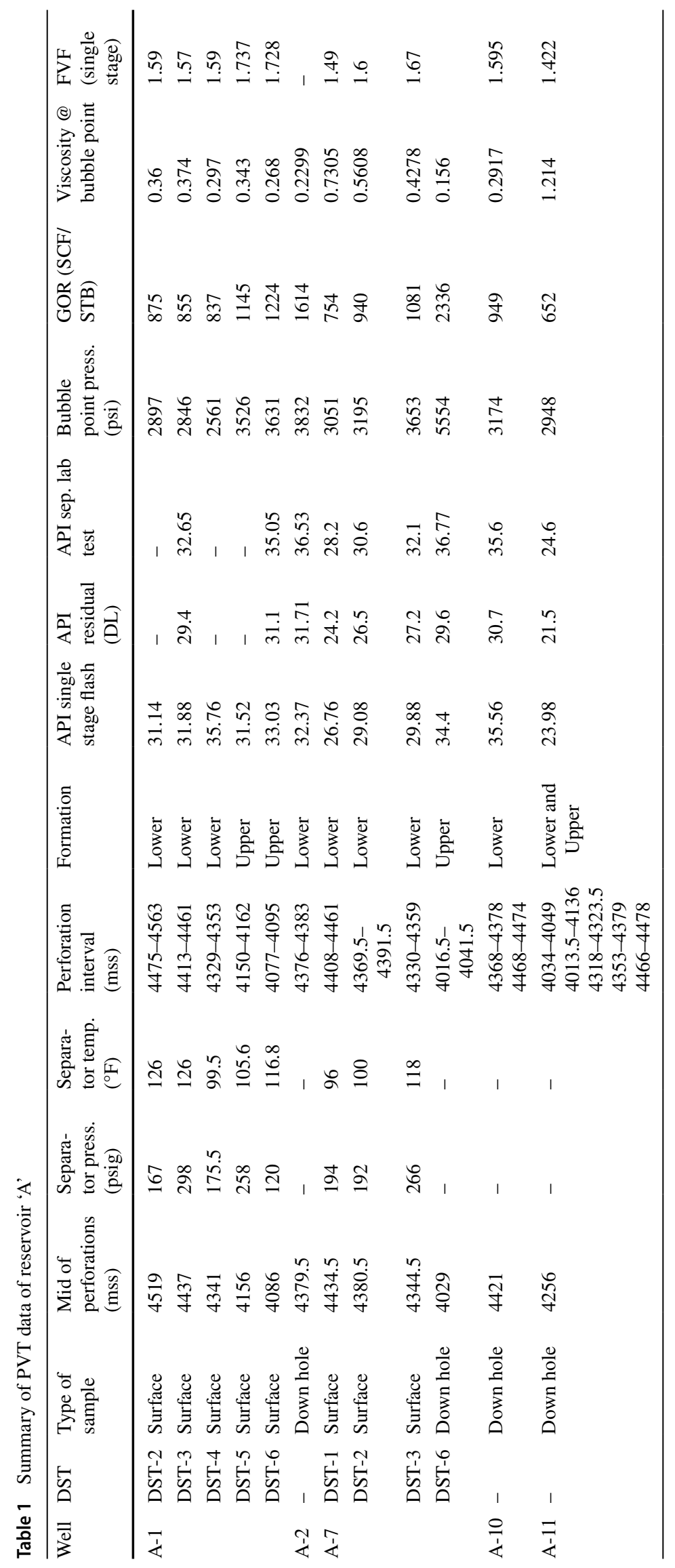


Table 2 Summary of FBDSTs of reservoir 'A'

\begin{tabular}{|c|c|c|c|c|c|c|c|c|c|c|}
\hline WELL & DST & $\begin{array}{c}\text { Ave. } \\
\text { Production } \\
\text { Depth (mss) }\end{array}$ & $\begin{array}{c}\text { FWHP } \\
\text { (psi) }\end{array}$ & $\begin{array}{c}\text { Separator } \\
\text { Press. (psig) }\end{array}$ & $\begin{array}{c}\text { Rate } \\
\text { (STB/day) }\end{array}$ & $\begin{array}{c}\text { Oil } \\
\text { Gravity } \\
\left({ }^{\circ} \mathrm{API}\right)\end{array}$ & $\begin{array}{c}\text { GOR } \\
\text { (SCF/STB) }\end{array}$ & $\begin{array}{c}\text { Perforation } \\
\text { Interval (mss) }\end{array}$ & Formation & Remarks \\
\hline \multirow{23}{*}{ A-1 } & \multirow{7}{*}{2} & 4494.8 & 568 & 151 & 2340 & 29.5 & 531 & \multirow{7}{*}{$4475-4563$} & \multirow{7}{*}{ Lower } & \multirow{7}{*}{-} \\
\hline & & 4494.8 & 1657 & 241 & 1843 & 30 & 625 & & & \\
\hline & & 4494.8 & 1900 & - & 1497 & 30.7 & 659 & & & \\
\hline & & 4494.8 & 1694 & - & 1920 & 30 & 698 & & & \\
\hline & & 4494.8 & 1322 & - & 2395 & 29.7 & 728 & & & \\
\hline & & 4494.8 & 1067 & - & 3371 & 29.4 & 710 & & & \\
\hline & & 4494.8 & 814 & - & 4144 & 31 & 671 & & & \\
\hline & \multirow{6}{*}{3} & 4437.1 & 1839 & - & 2000 & 32 & 646 & \multirow{6}{*}{$4413-4461.5$} & \multirow{6}{*}{ Lower } & \multirow{6}{*}{ - } \\
\hline & & 4437.1 & 1992 & - & 1541 & 32.5 & 707 & & & \\
\hline & & 4437.1 & 1659 & - & 2434 & 31.4 & 618 & & & \\
\hline & & 4437.1 & 1450 & - & 3403 & 30.2 & 517 & & & \\
\hline & & 4437.1 & 1270 & - & 3296 & 29.4 & 573 & & & \\
\hline & & 4437.1 & 1318 & - & 3214 & 30 & 601 & & & \\
\hline & 4 & 4341.3 & 710 & - & 994 & 36.5 & 623 & $4329-4354$ & Lower & - \\
\hline & \multirow{3}{*}{5} & 4156.4 & 1038 & - & 2466 & 31.5 & 561 & \multirow{3}{*}{$4150-4163$} & \multirow{3}{*}{ Upper } & \multirow{3}{*}{-} \\
\hline & & 4156.4 & 302 & - & $\mathrm{n} / \mathrm{a}$ & 31.5 & - & & & \\
\hline & & 4156.4 & 552 & - & 2503 & 28.5 & 817 & & & \\
\hline & \multirow{6}{*}{6} & 4085.8 & 1061 & - & 1918 & 33.7 & 1044 & \multirow{6}{*}{$4077-4095$} & \multirow{6}{*}{ Upper } & \multirow{6}{*}{ - } \\
\hline & & 4085.8 & 1860 & - & 1290 & 32.11 & 983 & & & \\
\hline & & 4085.8 & 1540 & - & 1529 & 33 & 971 & & & \\
\hline & & 4085.8 & 1328 & - & 1780 & 33 & 949 & & & \\
\hline & & 4085.8 & 980 & - & 2025 & 33 & 960 & & & \\
\hline & & 4085.8 & 958 & - & 2095 & 33 & 999 & & & \\
\hline \multirow{6}{*}{ A-2 } & \multirow{6}{*}{ - } & 4381 & 2117 & 421 & 2037 & 32 & 37 & \multirow{3}{*}{$4378-4384$} & \multirow{3}{*}{ Lower } & \multirow{3}{*}{-} \\
\hline & & 4381 & 1768 & 432 & 3907 & 31 & 863 & & & \\
\hline & & 4381 & 1565 & 472 & 5257 & 31 & 1284 & & & \\
\hline & & 4121 & 2157 & 371 & 2175 & 35 & 456 & \multirow{3}{*}{$4118-4124$} & \multirow{3}{*}{ Upper } & \\
\hline & & 4121 & 2067 & 399 & 2701 & 35 & 628 & & & - \\
\hline & & 4121 & 1926 & 397 & 3623 & 34 & 728 & & & \\
\hline & & 4287 & 692 & 242 & 1466 & 24.5 & 403 & & & \\
\hline A-3 & - & 4287 & 728 & 203 & 1561 & 25 & 330 & $4181-4393$ & Upper + Lower & PLT Sharing: $40 \%$ Lower, $60 \%$ Upper \\
\hline & & 4287 & 590 & 203 & 1900 & 26 & 310 & & & \\
\hline & & 4392 & 2089 & 411 & 2256.5 & 36 & 709 & & Upper + Lower, & \\
\hline & & 4392 & 1711 & 436 & 3313 & 35 & 1026 & & before acidizing & \\
\hline$A-6$ & 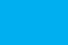 & 4392 & 2159 & 385 & 2180 & 34.5 & 693 & 402750505 & & PLT Sharing: 99 \% Lower, $1 \%$ Upper; Average \\
\hline & & 4392 & 1970 & 401 & 3490 & 34.7 & 768 & | & Upper + Lower, & $\begin{array}{l}\text { results } \\
\text { restich }\end{array}$ \\
\hline & & 4392 & 1867 & 398.5 & 3595 & 34.8 & 1039 & & after acidizing & \\
\hline & & 4392 & 1749 & 433.5 & 3576 & 35 & 1580 & & & \\
\hline
\end{tabular}

down-hole wells during FBDSTs is presented. Table 2 shows flowing well head data which are measured on well site during well test by portable separator of a few wells. It is important to mention that in all wells, in addition to penetrating main section of Lower part of reservoir; entire Upper part of reservoir is drilled without encountering any evidence of aquifer in this (upper) part of the reservoir, neither from static data (petrophysical logs) nor dynamic data (well tests).

Notwithstanding faults and an argillaceous limestone layer which could explain diverseness of fluid properties in different parts of the reservoir, a few questions have been raised about diversity of fluid properties through the 
Table 2 (continued)

\begin{tabular}{|c|c|c|c|c|c|c|c|c|c|c|}
\hline WELL & DST & $\begin{array}{c}\text { Ave. } \\
\text { Production } \\
\text { Depth }(\mathrm{mss})\end{array}$ & $\begin{array}{c}\text { FWHP } \\
\text { (psi) }\end{array}$ & $\left|\begin{array}{c}\text { Separator } \\
\text { Press. (psig) }\end{array}\right|$ & $\begin{array}{c}\text { Rate } \\
\text { (STB/day) }\end{array}$ & $\begin{array}{c}\text { Oil Gravity } \\
\text { ('API) }\end{array}$ & $\begin{array}{c}\text { GOR } \\
\text { (SCF/STB) }\end{array}$ & $\begin{array}{c}\text { Perforation } \\
\text { Interval (mss) }\end{array}$ & Formation & Remarks \\
\hline \multirow{12}{*}{ A-7 } & \multirow{4}{*}{1} & 4433.5 & 514 & 156 & 1208 & 23 & 569 & \multirow{4}{*}{$4408-4461$} & \multirow{4}{*}{ Lower } & \multirow{4}{*}{ - } \\
\hline & & 4433.5 & 788 & 194 & 1449 & 26.9 & 555 & & & \\
\hline & & 4433.5 & 668 & 201 & 1559 & 24.6 & 559 & & & \\
\hline & & 4433.5 & 758 & 204 & 1749 & 25.5 & 539 & & & \\
\hline & \multirow{4}{*}{2} & 4380.5 & 621 & 151 & 1882 & 31.5 & 660 & \multirow{4}{*}{$-4369.5-4391.5$} & \multirow{4}{*}{ Lower } & Before acid \\
\hline & & 4380.5 & 1108 & 249 & 2505 & 22.5 & 581 & & & \multirow{3}{*}{ After Acid } \\
\hline & & 4380.5 & 966 & 250 & 2871 & 23 & 611 & & & \\
\hline & & 4380.5 & 878 & 252 & 3055 & 25.2 & 628 & & & \\
\hline & \multirow{2}{*}{3} & 4344.5 & 1574 & - & 1544 & 29 & 986 & \multirow{2}{*}{$4330-4359.5$} & \multirow{2}{*}{ Lower } & \multirow{2}{*}{ After Acid } \\
\hline & & 4344.5 & 860 & - & 3296 & 28.2 & 801 & & & \\
\hline & 4 & 4310.5 & & - & 607 & 36.8 & 1028 & $4297.5-4320$ & Lower & - \\
\hline & 6 & 4028.5 & & - & 360 & 35.6 & 947 & $4016.5-4941.5$ & Upper & - \\
\hline \multirow{9}{*}{ A- 8} & - & 4061 & 693 & 141 & 3054 & 23.5 & 607 & \multirow{9}{*}{$4057.8-4499.5$} & \multirow{9}{*}{ Upper + Lower } & \multirow{2}{*}{ Before acid } \\
\hline & - & 4061 & 787 & 139 & 2843 & 24.7 & 590 & & & \\
\hline & - & 4061 & - & - & 4483 & 32 & - & & & \\
\hline & - & 4061 & 2525 & 453 & 4568 & 34.8 & 1388 & & & \\
\hline & - & 4061 & 2342 & 451 & 3458 & 32.4 & 2829 & & & After acid \\
\hline & - & 4061 & 2718 & 418 & 3961 & 34 & 882 & & & \\
\hline & - & 4061 & 2558 & 441 & 4666 & 34.6 & 1072 & & & \\
\hline & - & 4061 & 2815 & 414 & 2674 & 35.4 & 941 & & & $\begin{array}{l}\text { PLT. Sharing: } 97 \% \text { from Upper. From PLT, the } \\
\text { surface rate was } 3400 \mathrm{STB} / \text { day. }\end{array}$ \\
\hline & - & 4061 & 2323 & 457 & 2476 & 33.5 & - & & & $\begin{array}{l}\text { PLT. Sharing: } 88 \% \text { from Upper, } 12 \% \text { from Lower. } \\
\text { From PLT, the surface rate is } 7900 \mathrm{STB} / \text { day. }\end{array}$ \\
\hline \multirow{3}{*}{ A-10 } & - & 4373 & 1839 & 420 & 1915 & 32.4 & 644 & \multirow{3}{*}{$4368-4378$} & \multirow{3}{*}{ Lower } & \multirow{3}{*}{ - } \\
\hline & - & 4373 & 1510 & 419 & 3692 & 31.4 & 667 & & & \\
\hline & - & 4373 & 1266 & 407 & 4644 & 31.2 & 704 & & & \\
\hline \multirow{5}{*}{ A-11 } & - & 4268.5 & 900 & 407 & 2800 & 29 & 666 & \multirow{5}{*}{$4034-4503$} & \multirow{5}{*}{$\mathrm{L}+\mathrm{U}$} & Before acid \\
\hline & - & 4268.5 & 1448 & 399 & 1943 & 29 & 675 & & & \\
\hline & - & 4268.5 & 1375 & 403 & 2880 & 26 & 680 & & & After acid \\
\hline & - & 4268.5 & 1293 & 398 & 3930 & 26 & 680 & & & \\
\hline & - & 4268.5 & 1331 & 391 & 4097 & 26 & 675 & & & PLT sharing: $53 \%$ from Upper, $47 \%$ from Lower \\
\hline & - & 4261 & 2020 & 527 & 2606 & 29 & 192 & & & \\
\hline & - & 4261 & 2021 & 551 & 2706 & 29 & 200 & & & \\
\hline & - & 4261 & 1817 & 536 & 4009 & 29 & 400 & & & \\
\hline & - & 4261 & 1810 & 534 & 4059 & 29 & 410 & & & \\
\hline 10 & - & 4261 & 1805 & 537 & 4034 & 29 & 416 & 40255411 & $I_{-1}$ & 10 \\
\hline $\mathrm{A}-12$ & - & 4261 & 1683 & 530 & 4677 & 28 & 316 & $4035.3-44 / 1.5$ & Lower + Opper & Aller acid \\
\hline & - & 4261 & 1675 & 580 & 4911 & 28 & 360 & & & \\
\hline & - & 4261 & 1672 & 584 & 4635 & 28 & 384 & & & \\
\hline & - & 4261 & 1679 & 588 & 4585 & 28 & 393 & & & \\
\hline & - & 4261 & 1630 & 667 & 5220 & 28 & 379 & & & \\
\hline
\end{tabular}


reservoir: why the GOR and API gravities are so different in two wells which are just a few kilometers far away from each other; however, in some wells, the fluid properties, even in one well, in Upper and Lower parts are similar? For better understanding seed of these questions please refer to Fig. 1 and Tables 1 and 2. For example; compare wells 'A-6' and 'A-10': oil API gravity of well 'A-6' is in the range of $35^{\circ}-36^{\circ}$ but oil API gravity of well 'A-10' is reported to be in the range of $31^{\circ}-32^{\circ}$. Also, in each wells of 'A-1' and 'A-7' which different reservoir section are separately tested, one can find about same oil API gravity in Upper and Lower parts of the reservoir.

Another question which has been raised and may be answered by reviewing reservoir's fluid properties is: Are the faults conductive (if any)? It can be answered by comparing produced oil properties of wells located across two sides of a fault. If measured produced fluid properties of wells (such as wells 'A-7' and 'A-4') are similar; then, it can be said that the fault is conductive at least at geological time.

Also two scenarios, which have a great influence on the oil in place estimation and reservoir management, have been raised: some experts postulated that both Upper and Lower parts of the reservoir are in communication with each other through at least at a 'shared aquifer' and others supposed each part of the reservoir has its own aquifer. To mitigate these types of uncertainties and to answer raised questions mentioned above, a study is conducted which a brief of its results are presented in following sections.

\section{Methodology}

For a technical/scientific study, having a methodology is a 'must'. In this work, as a lot of measured data are generated and reported, three steps are considered as basis of this study:

- Investigate the validity of data,

- Postulate a theory about the validated data,

- Justify the outlier data.

\section{Validity of data}

In this work, two sets of data are provided:

- Properties of fluid samples such as oil API gravity, fluid's bubble point pressure, and reservoir fluid's composition which are measured in laboratory and reported in PVT test results of gathered down-hole or surface fluid samples (Table 1).

- Properties of produced oil and gas such as oil API gravity, well flow rate, well head pressure, and GOR which are measured on well site during production tests or FBDSTs (Table 2).

Measured on well site oil densities during conducting FBDSTs campaign can be considered to be reliable in the range of engineering measurements; as they are carried out on the degassed oil sample and repeated several times in a test period. Nonetheless, these type of data, in addition to human error, are subjected to measured errors in measurement of separator's operating pressure and temperature. These errors will affect the on well site measurement of produced oil density (reported API gravity), and this issue will be explained in next sections. However, the measured data during a PVT test on a fluid sample in a laboratory are more susceptible to different source of errors; especially, it is more true for those PVT data obtained from recombination of surface oil and gas samples (Standing 1981). One method to check the validity, accuracy and correctness of reported PVT data of a reservoir is the suggestion of Whitson and Brule (2000) and (Ahmed 2007). Watson characterization factor is introduced and defined by Watson et al. (1935) and (Ahmed 2007) as follows:

$K_{\mathrm{w}}=\frac{T_{\mathrm{b}}^{1 / 3}}{\mathrm{SG}}$,

where: $K_{\mathrm{w}}$ Watson characterization factor, $T_{\mathrm{b}}$ normal boiling point temperature; ${ }^{\circ} R$, SG specific gravity at $60^{\circ} \mathrm{F}$.

This factor is widely used for characterizing the crude oil and its products (Nelson 1958). This factor roughly ranges as paraffin-predominant $\left(K_{\mathrm{w}}=12.0-12.5\right)$, naphthenicpredominant $\left(K_{\mathrm{w}}=11-12\right)$, and aromatic-predominant $\left(K_{\mathrm{w}}=10-11\right)$, (Chilingarian et al. 1987). Other authors reported wider range values for this factor (Nelson 1958; Ahmed 2007). It is suggested by Whitson (1980) that for the heptane-plus fraction, the Watson characterization factor to be calculated using only molecular weight and gravity of 'C7+', as follows:

$K_{\mathrm{w}} \approx 4.5579 \frac{\mathrm{MW}^{0.15178}}{\mathrm{SG}^{0.84573}}$,

where 'MW' is molecular weight and other variables defined as above.

Whitson and Brule (2000), based on their observations suggested that a plot of molecular weight versus specific gravity of the plus fractions is useful for checking the consistency of 'C7+' molecular weight and specific gravity measurements. By taking logarithm from both sides of Eq. (2), it becomes:

$$
\begin{aligned}
\log \left(K_{\mathrm{w}}\right)= & \log (4.5579)+0.15178 \times \log (\mathrm{MW}) \\
& -0.84573 \times \log (\mathrm{SG}) .
\end{aligned}
$$

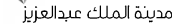
للعلومر والتقنية عبدالعزيز 
Apply some manipulation, Eq. (3) changes to:

$\log (\mathrm{MW})=\frac{1}{(0.15178)} \times \log \left(\frac{K_{\mathrm{w}}}{4.5579}\right)+\frac{0.84573}{0.15178} \times \log (\mathrm{SG})$.

Or in general form, it can be written as follows:

$\log (\mathrm{MW})=c+n \times \log (\mathrm{SG})$.

Or

$\mathrm{MW}=c^{\prime}(\mathrm{SG})^{n}$.

The above equations indicate that plotting molecular weight (MW) of heptane plus $(\mathrm{C} 7+)$ versus its specific gravity (SG) for a series of PVT samples data (on a log-log scale) should fall on a straight line. Austad et al. (1983) and Whitson and Brule (2000) presented this observation by plotting MW versus SG for 'C7+' fractions from data on two North Sea fields (Ahmed 2007).

To verify consistency of available PVT data, reported molecular weights of ' $\mathrm{C} 7+$ ' are plotted versus 'SG'. As it is shown in Fig. 2, there is adequate consistency in reported PVT data to rely on them in the engineering accuracy requirement. It should be noted that the Austad et al. (1983) and Whitson and Brule (2000) plots are on the Cartesian coordinates and for short range of data, one straight line can also be passed through the points (see Fig. 2).

\section{Results and discussion}

To ascertain the relationship of between API gravity of reservoir oil and depth (if any), measured API gravity values of FBDSTs and PVT lab tests are plotted versus subsea depth as shown in Figs. 3 and 4. At the first glance, it seems the data are scattered; however, by more careful examination of the plotted data and remembering reported PLTs (Production Logging Tool) results (please refer to Table 2, remarks of wells 'A-3', 'A-6', 'A-8' and 'A-11'), two separate but parallel lines can be drawn through the data points.

Composition of reservoir fluid has a great effect on its vertical distribution; however, it consists of a lot of hydrocarbon components; from light methane to very heavy components. The provided composition of reservoir oils are from 'C1' to ' $\mathrm{C} 7+$ '. To investigate effect of all these number of components (7 standard hydrocarbon components, ' $\mathrm{C} 6$ ' and ' $\mathrm{C} 7+$ ') on the density variation of reservoir oil requires a tremendous effort which seems unnecessary as physical properties of some of them are similar. The composition of a reservoir's oil can be categorized in three main groups: light components, intermediate components and heavy components. In this work, the reported composition of each PVT set of data are lumped in three major pseudo-components: ' $\mathrm{C} 1+\mathrm{C} 2$ ' (methane plus ethane), 'C3-C6' (propane to hexanes) and ' $\mathrm{C} 7+$ '. The mole fraction of these pseudocomponents are plotted against True Vertical Depth (TVD), see Fig. 5. As composition segregation is taken place under influence of gravity, in Fig. 6 weight fraction of pseudocomponents are also plotted. As by reducing the variables, comparison and making judgement about one phenomenon would be more simple and deducible, all components are also lumped in just two pseudo-components: 'C1-C6' and 'C7+', and plotted in Fig. 7. The plotted data in Figs. 5, 6 and 7 are extracted from PVT set of data mentioned in Table 1; however, a few of FBDSTs mentioned in this table have more samples. To increase reliability of conclusion, all reported data on different samples of one FBDST are used and plotted in these figures.
Fig. 2 Reported C7+molecular weight and specific gravity of the reservoir PVTs

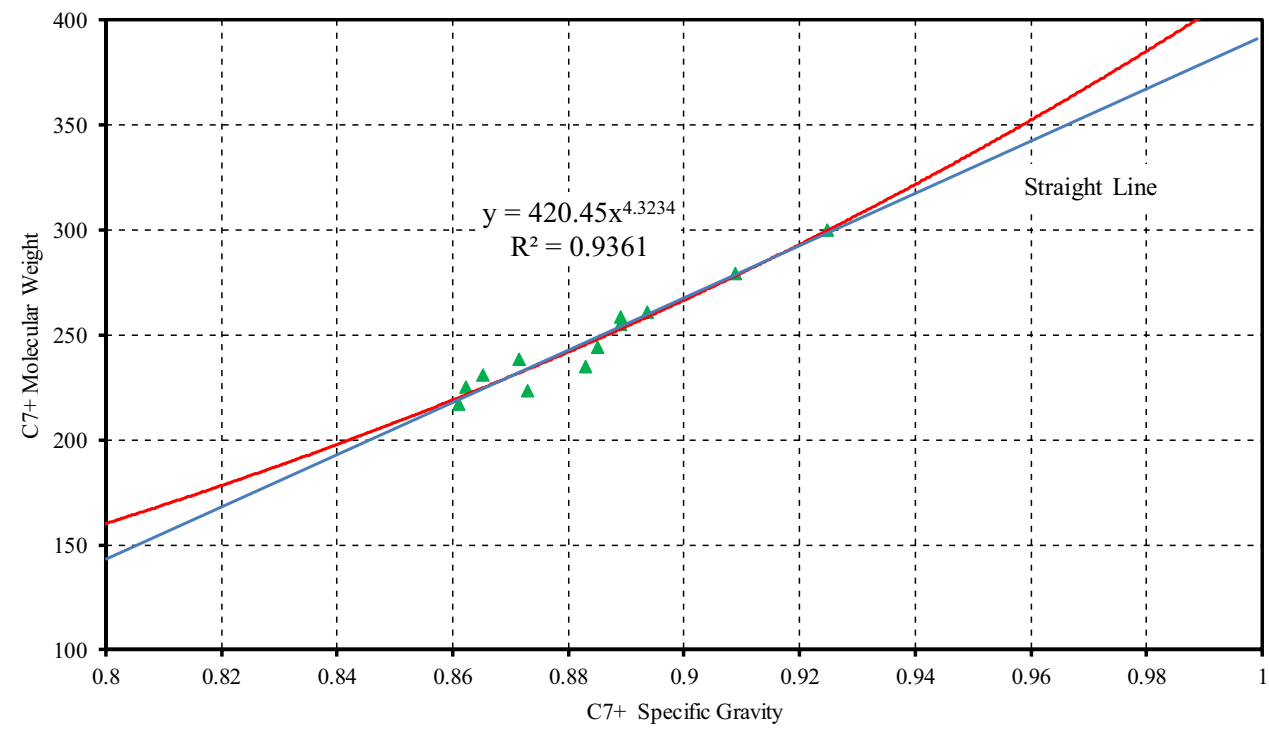

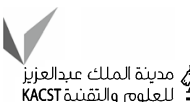


Fig. 3 Measured oil API gravities during FBDSTs
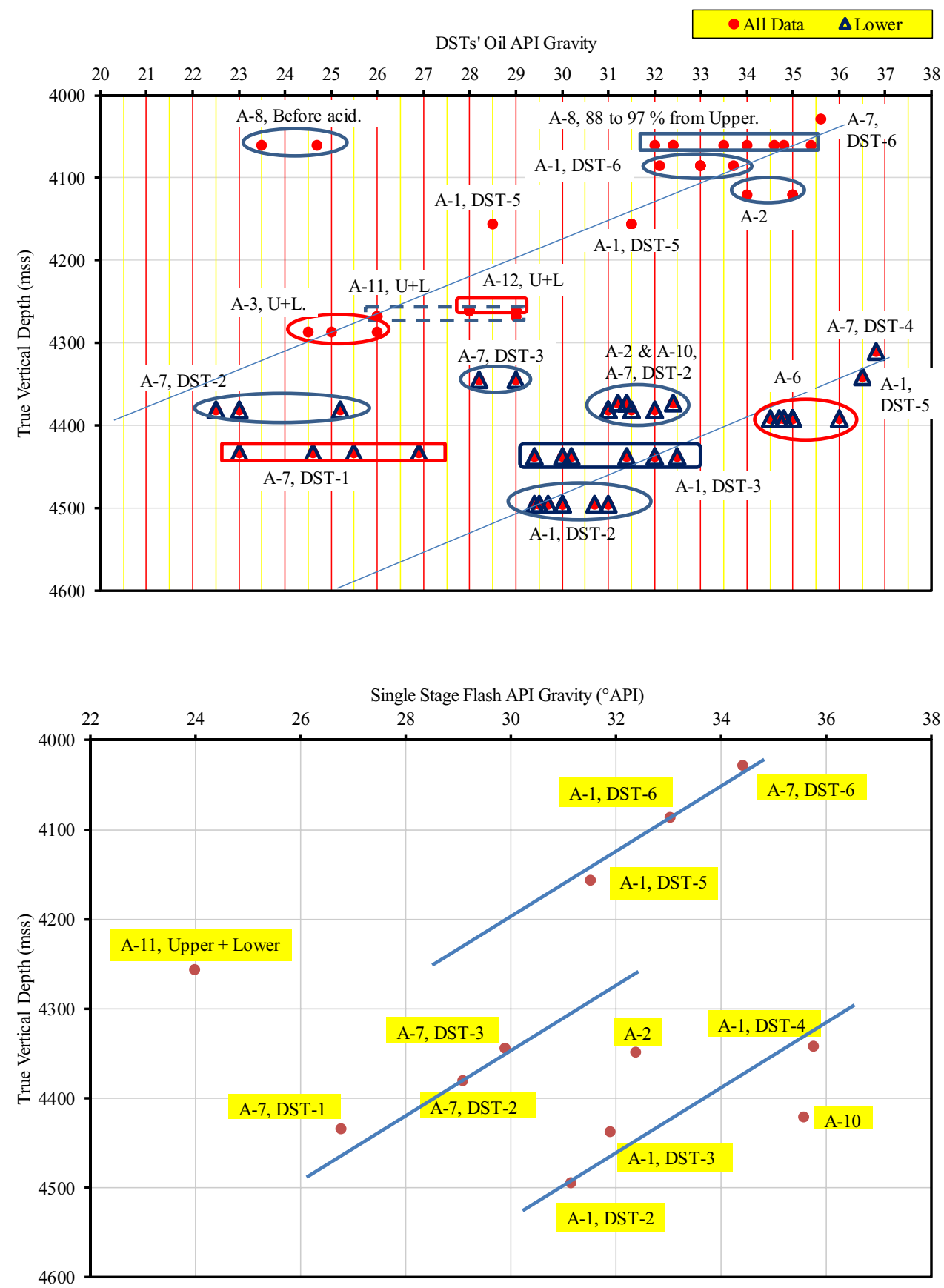

Fig. 4 Measured single stage flash API gravities of reservoir oil samples during PVT tests
From the plotted data of this reservoir in Figs. 3, 4, 5, 6 and 7 (which are supporting each other), one can conclude that this reservoir vertically consists of two completely separated parts which is in agreement with geological information about the argillaceous limestone. Remember that this layer acts a barrier in neighbor fields. Also, it can be said that there is a vertical fluid composition variation in each part of the reservoir. But what can be commented about horizontal composition variation?

As it is mentioned, there are some challenges to define and characterize the fluid of carbonate reservoirs. Ghorayeb and Firoozabadi (2000) reviewed several papers and reported that different trend of compositional variation can be distinguished: vertical compositional variation, pronounced horizontal compositional variation, and very little compositional variation with depth in different fractured carbonate reservoirs. By careful looking at the plotted data of the reservoir 'A' (Figs. 3, 4, 5, 6 and 7) and location of wells in Fig. 1 (such as wells 'A-1', 'A-7' and 'A-11'), one can judge that although vertical composition variation in this reservoir is predominant; however, no or a small scale horizontal composition variation can be assigned to the reservoir. 
Fig. 5 Vertical reservoir fluid distribution (mole percent)

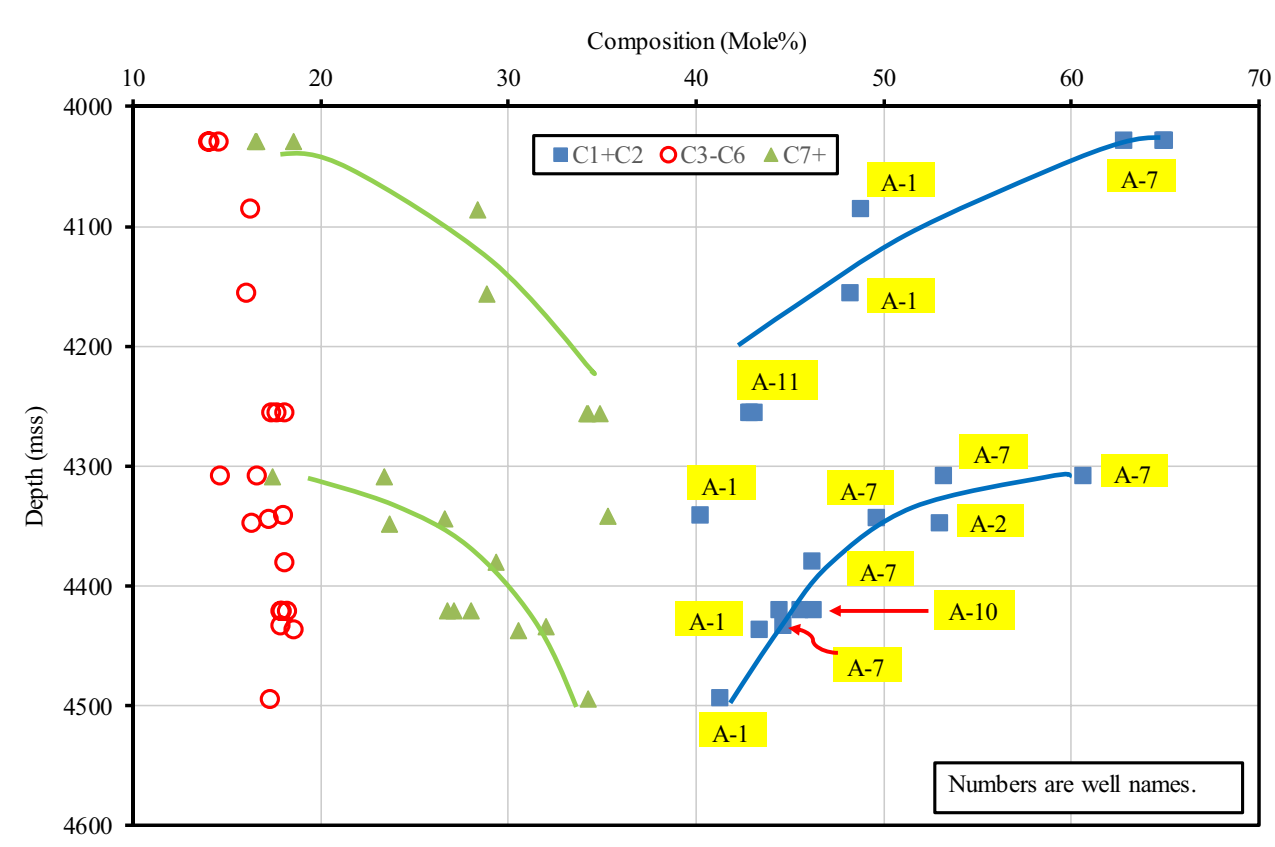

Fig. 6 Vertical reservoir fluid distribution (weight percent, three pseudo-component)

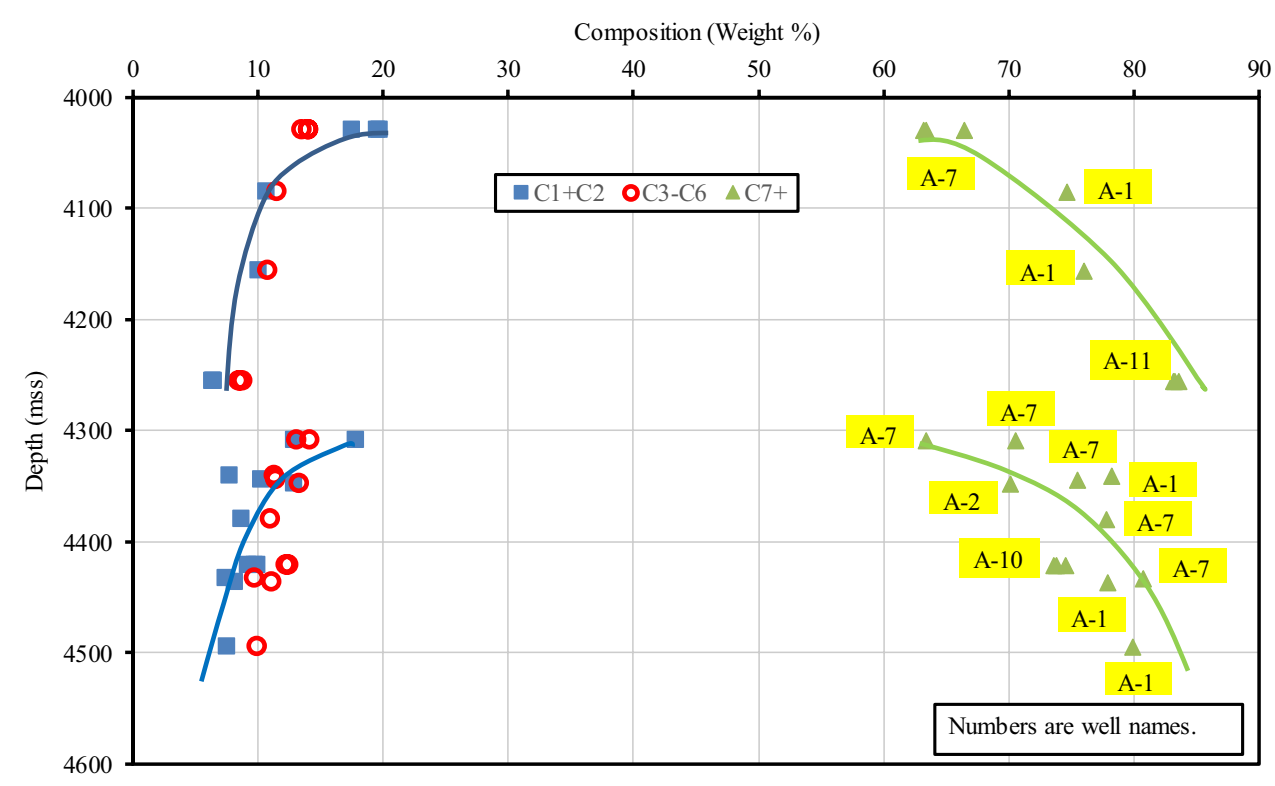

Based on the deduction of existing vertical composition variation in each part of the reservoir and by considering the thickness of each parts (Upper and Lower) of the reservoir (about $300 \mathrm{~m}$ thickness of each part), it sounds reasonable to conclude that the fissures in this reservoir are not effectively conductive in vertical direction; because, if they were conductive it would be expected that convection phenomenon to take place. This convection eliminates or at least mitigates the vertical fluid composition variation of the reservoir, at geological times.

By carefully looking at Figs. 3, 4, 5, 6 and 7, one important point can be drawn: The slope of oil specifications' variation with depth is obviously the same in Upper and Lower parts of the reservoir, however, with some displacement. This point implies that both Upper and Lower parts of the reservoir are fed from same origin source rock. On the other hand, as it is mentioned in previous section, based on down-hole pressure measurement during well transient tests and data obtained from running MDT/XPT tools, it was concluded that one reservoir pressure system exists throughout the entire vertical reservoir section, from top of Upper part to bottom of Lower part. Based on these facts, one can deduce that although the argillaceous limestone member acts as a seal layer and vertically divides the reservoir to two 
Fig. 7 Vertical reservoir fluid distribution (weight percent, two pseudo-components)

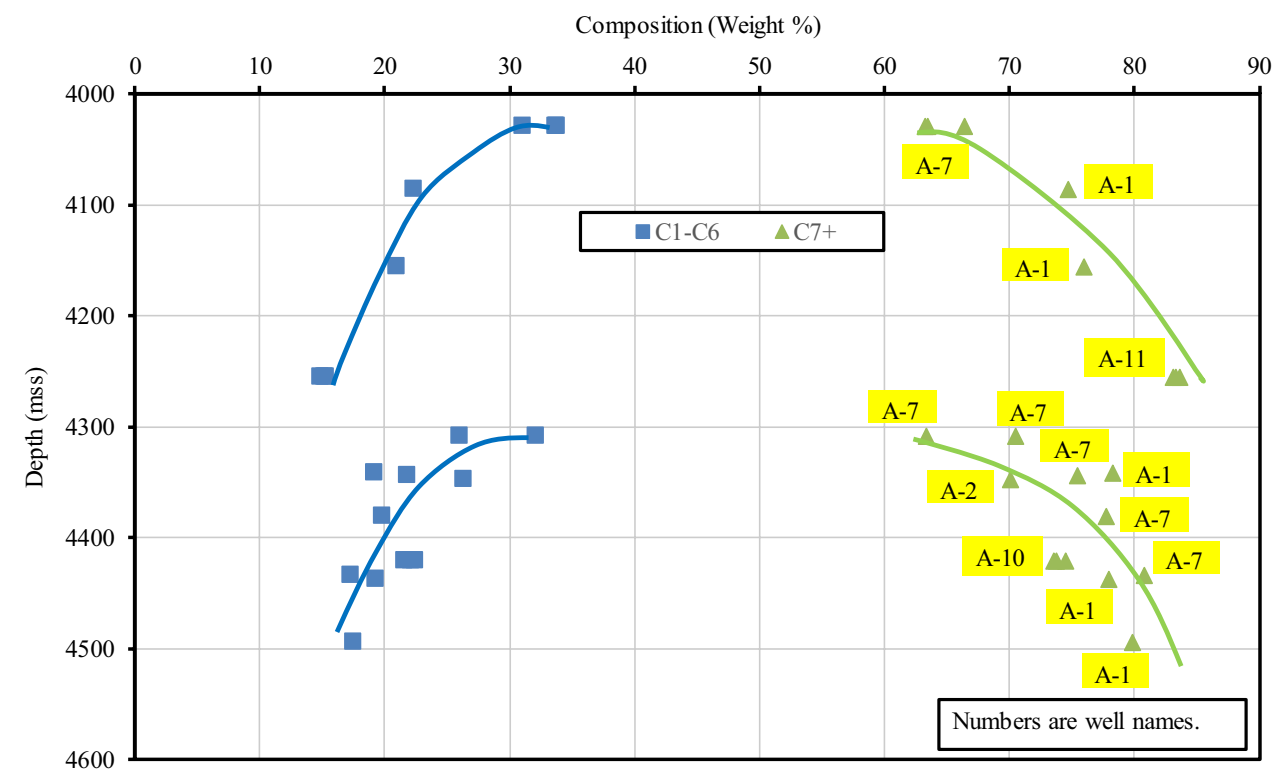

parts; however, both these parts would potentially communicate through same aquifer.

Also, based on the geological-geophysical studies, it is believed that a few faults penetrate formation 'A' (see Fig. 1). Based on the data presented in Figs. 3, 4, 5, 6 and 7 and considering the wells which located on the opposite sides of detected faults such as wells 'A-1', 'A-4', 'A-6' and 'A-7' (see Fig. 1), it can be pointed that these faults are not potentially barriers, at least in a geological time. The oil properties of these wells (such as API gravity and composition) follow the same trends.
The formation thickness variation of Upper and Lower parts of reservoir ' $A$ ' is shown in Fig. 8. This figure reveals that the top layers' depths of the reservoir 'A' do not significantly vary in lateral extent. So, based on the above discussed results (existing an equal slope of linear fluid properties change with depth in both separated parts of the reservoir), it sounds reasonable to judge following points:

- It is satisfactory to encounter oil with same API gravities in different wells in the same sub-layers because sea level depth is more or less the same. Note: Upper and Lower
Fig. 8 Wells top formation of reservoir 'A'

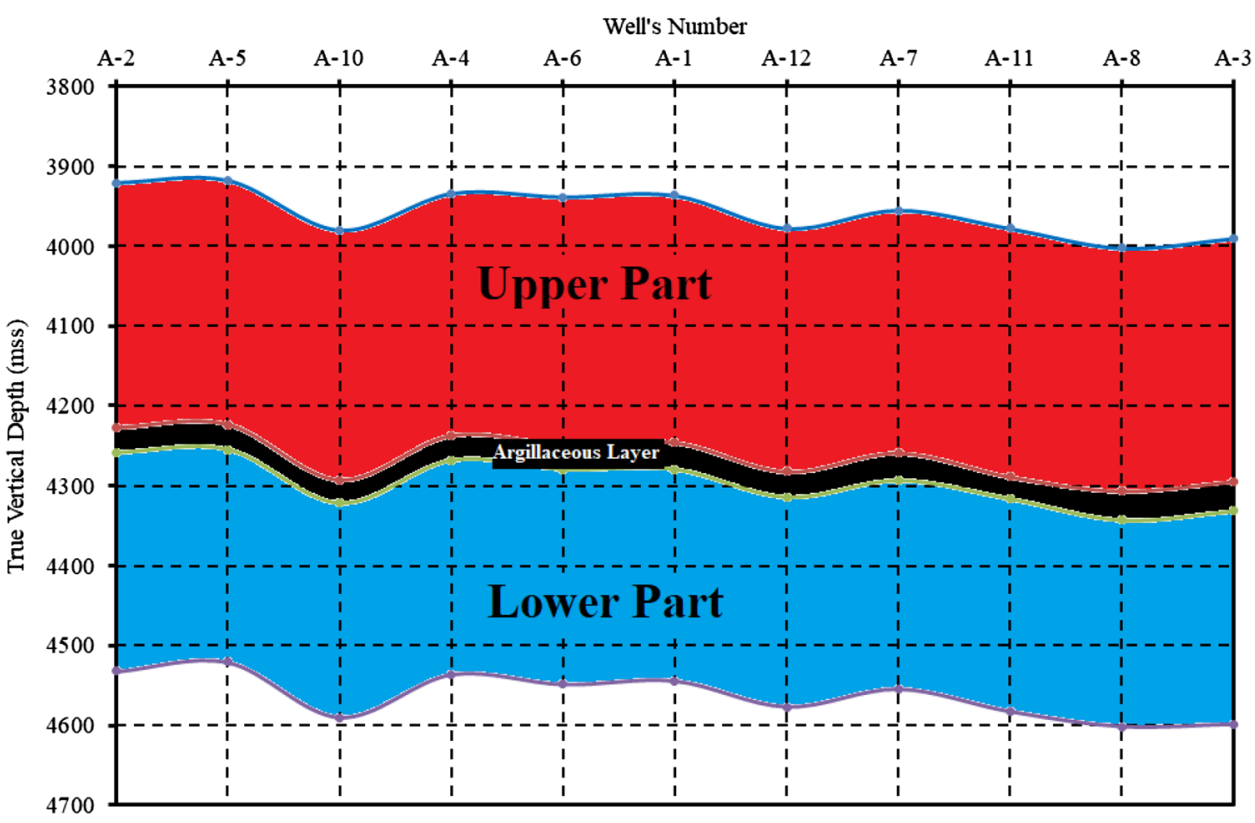


parts of the reservoir are geologically divided to different sub-layers.

- It is sensible to encounter oil with same API gravities in one well but in different sub-layers of Upper and Lower parts as slope of oil property change with depth of the both parts is equal.

- Encountering oil with different API gravity in two adjacent wells (even in one part of the reservoir) can be justified with considering a rapid change of oil properties with depth and vertical thickness of each part of the reservoir which is about $300 \mathrm{~m}$.

- Also, it is logic to make a prediction encountering a heavy oil (about $20^{\circ}$ API) in deeper wells, near base of the Upper or Lower parts of the reservoir. It is worth mentioning that this prediction becomes true in next drilled wells.

There are few points which should be considered, assessed and explained. First point which worth to mention is the difference in measured on well site API gravities of oil in one FBDST; for example, see Table 2 and Fig. 3, FBDST-1 of 'A-7' well and FBDST-2 of 'A-1' well. This difference can be raised from different sources:

1. Error in measurement,

2. inherent fluid behavior when subjected to different pressure and temperature,

3. different perforated intervals come to production due to different down-hole drawdown,

4. or combination of all of them.
To examine the second source of error, two PVT sets with different oil and gas properties are subjected to different separator pressures and temperatures by using a simulation software. Figure 9 shows the results of PVT simulation by HYSIS package. In this simulation, two sets of PVT data are used: one data of sample gathered during conduction FBDST-1 of 'A-7' well with API gravity around $28^{\circ}$ and another one data of sample obtained during conducting FBDST- 6 of the same well with API gravity about $36^{\circ}$ (see Table 1). In the simulation, two models are considered; in one model, the well stream flows to a separator with operating temperature equal to $80^{\circ} \mathrm{F}$ and in other model, operating temperature is set to be $120^{\circ} \mathrm{F}$ ). The models were run for different separator operating pressure (see Fig. 10 for schematic of this simulation). The results (see Fig. 9) show that in the considered range of temperature and pressure, the maximum API variation for one specified set of production intervals would be about $2^{\circ}$ of API. So, it seems that the second type of source of error could not be the main source.

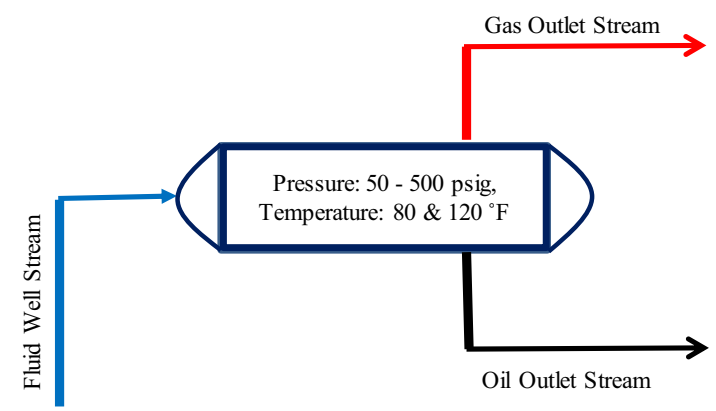

Fig. 10 Schematic separator simulation
Fig. 9 HYSIS simulation model for two different sets of PVT data

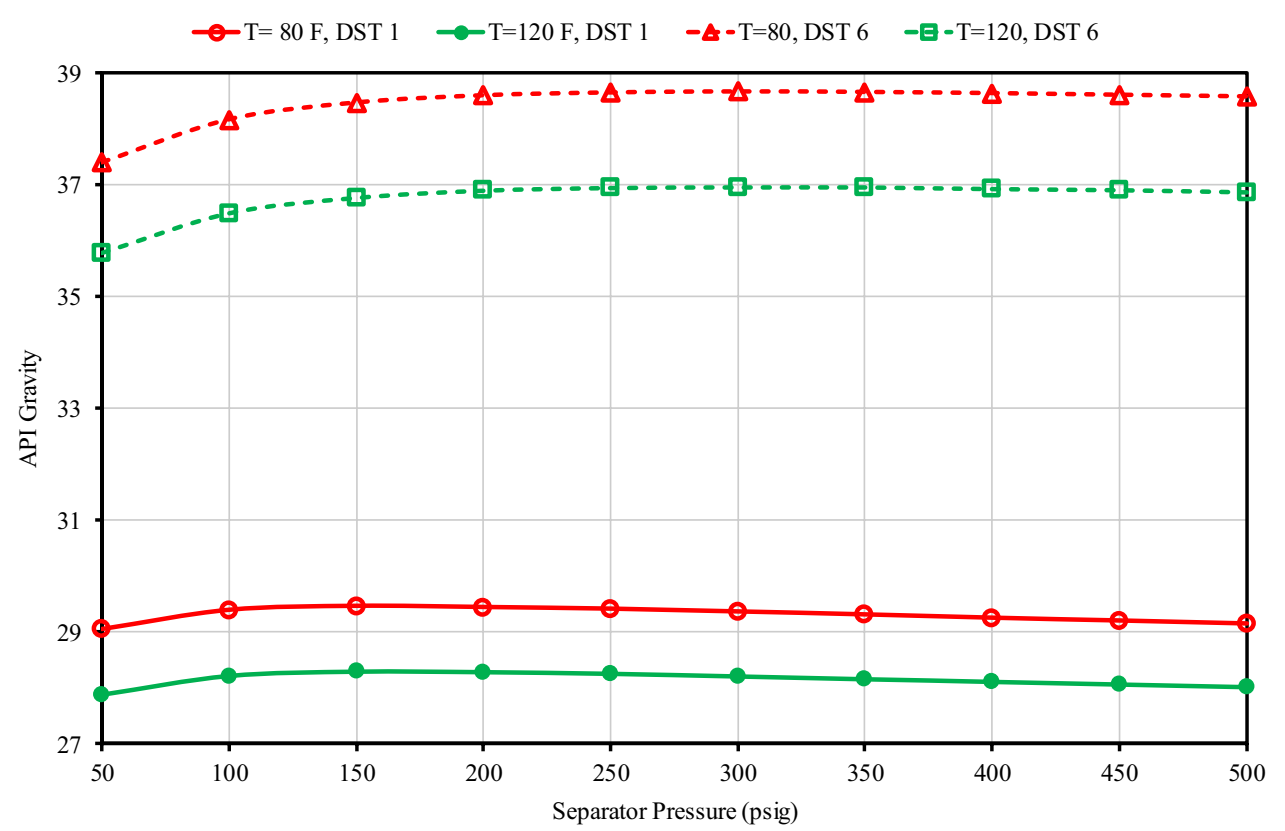


During DST-1 of 'A-7' well, three sets of perforation were open to flow: 4408.5-4415 mss, 4425.5-4432 mss, and 4455-4461.5 mss (in Tables 1 and 2, perforated interval is mentioned 4408-4461 mss). The average perforated interval depth of each set is $4411.75,4428.75$, and $4458.25 \mathrm{mss}$, respectively. The average down-hole drawdown in each of four flow periods (mentioned in Table 2) is about 2589, 2064,2332 , and 2561, respectively (first rate test is measured before acid job operation). By looking at Figs. 3 and 4, it can be judged that the slope of API variation with depth is about ' $-4.00^{\circ}$ ' to ' $-5.00^{\circ}$ ' API/100 m. On the other hand, the average separator temperature variation during these four flow periods is reported to be around $15^{\circ} \mathrm{F}$. So, it seems that both change in magnitude of down-hole drawdown and change in operating separator conditions (temperature change) caused a variation in API gravity of produced oil, in addition to human error. Change in down-hole drawdown affects the production share of each set of perforations based on their permeability and each set of perforation produces its own API gravity oil (based on its depth); so, the produced mix oil gravity changes with down-hole drawdown.

Another point is that it seems API gravities of 'A-7' well during FBDSTs 1, 2, and 3 do not follow the general trend of API gravity variation with depth in reservoir 'A'; refer to Figs. 3 and 4, especially middle line which is drawn parallel to other two lines in Fig. 4. In FBDST-2 of this well and before acid job, API gravity is reported equal to $31.5^{\circ}$ which obeys the trend. As no any fault is seen in the vicinity of this well, it seems some errors in operation or measurement make this discrepancy. With reviewing other PVT results (refer to Figs. 5, 6, 7), more certainty is gained that the errors in measurement or operation caused this discrepancy.

\section{Conclusion and recommendation}

In this work by following a systematic approach, a real case of reservoir's fluid variation is investigated and answered questions raised in campaign of drilling and testing a few wells of the reservoir. Based on the results of this study, following points can be highlighted:

A. Oil properties of the reservoir vary with depth.

B. Existing two vertical separated parts in the reservoir.

C. Slope of oil specifications' variation with depth is obviously same in Upper and Lower parts; however, with some displacement.

D. Oil of two parts of the reservoir is probably migrated from a same source rock.

E. Both parts of the reservoir may be in communication through same aquifer.
F. Faults of the reservoir which are detected in geophysics/ geology study are not potentially barriers, at least in a geological time.

G. In deep wells, experiencing heavy oil with gravity as low as $20^{\circ}$ API is predictable.

H. If a thick section of the reservoir brings in production, by changing the flow rate (changing choke size), the producing oil specifications should be expected to be changed.

I. It can be predicted that a heavy oil layer exists at water oil contact in Lower part which would potentially reduce the aquifer strength to be effective on the reservoir performance (see point ' $G$ ' mentioned above).

J. Optimum dynamic reservoir management dictates to consider a well-balanced oil production from both parts of the reservoir; as it consists of two separate sections. In this regards, running periodical production sharing tools (e.g., PLT) and performing remedial activities (if necessary) are recommended.

Open Access This article is licensed under a Creative Commons Attribution 4.0 International License, which permits use, sharing, adaptation, distribution and reproduction in any medium or format, as long as you give appropriate credit to the original author(s) and the source, provide a link to the Creative Commons licence, and indicate if changes were made. The images or other third party material in this article are included in the article's Creative Commons licence, unless indicated otherwise in a credit line to the material. If material is not included in the article's Creative Commons licence and your intended use is not permitted by statutory regulation or exceeds the permitted use, you will need to obtain permission directly from the copyright holder. To view a copy of this licence, visit http://creativecommons.org/licenses/by/4.0/.

\section{References}

Ahmed T (2007) Equations of state and PVT analysis: applications for improved reservoir modeling. Gulf Publishing Company, Houston

Austad T, Hvidsten J, Norvik H, Whitson CH (1983) Practical aspects of characterizing petroleum fluids. In: North Sea condensate reservoirs and their development conference, London, 1983

Chilingarian GV, Robertson JO Jr, Kumar S (1987) Surface operations in petroleum production, I. Elsevier Science Publishers B.V., Amsterdam

Ghorayeb K, Firoozabadi A (2000) Features of convection and diffusion in porous media for binary systems. In: DOE/BC/14850-5, distribution category UC-122. Reservoir Engineering Research Institute, Palo Alto, CA, USA

Nelson WL (1958) Petroleum refinery engineering, 4th edn. McGrawHill, New York

Saidi AM (1987) Reservoir engineering of fractured reservoirs (fundamental and practical aspects). TOTAL Edition Presse, Paris

Standing MB (1981) Volumetric and phase behavior of oil field hydrocarbon systems, 9th edn. Society of Petroleum Engineers of AIME, Dallas

Watson KM, Nelson EF, Murphy GB (1935) Characterization of petroleum fractions. Ind Eng Chem 27(1935):1460-1463 
Whitson CH (1980) Characterizing hydrocarbon plus fractions. In: European offshore petroleum conference and exhibition, London, England. October 21-24, 1980

Whitson CH, Belery P (1994) Compositional gradients in petroleum reservoirs. In: University of Tulsa centennial petroleum engineering symposium, Tulsa, OK, USA, 29-31 August 1994. SPE paper 28000

Whitson CH, Brule MR (2000) Phase behavior. Society of Petroleum Engineers, Richardson
Publisher's Note Springer Nature remains neutral with regard to jurisdictional claims in published maps and institutional affiliations. 